\title{
O MUNDO VIVIDO NA GEOGRAFIA BRASILEIRA: SOBRE A INSTABILIDADE DE UM CONCEITO HUMANISTA-CULTURAL NO INÍCIO DO SÉCULO XXI
}

\author{
Sandro de Oliveira Safadi \\ Instituto Federal de Goiás, Laboratório de Ciências Sociais e Humanidade, Anápolis, GO, Brasil \\ sandro.safadi@ifg.edu.br
}

\begin{abstract}
RESUMO
Está em curso a construção do que é discutida neste trabalho como tendência humanistacultural da geografia brasileira, compreendida como um conjunto de produções que absorve a perspectiva plural no que se refere a influências metódicas e de marcos teóricos, além de um olhar voltado para o indivíduo. O estudo se dá a partir da análise da produção geográfica brasileira contemporânea, mais especificamente da primeira década do século $\mathrm{XXI}$, que utiliza como suporte teórico a noção de mundo vivido - presente nas formulações de autores anglo-saxões como Anne Buttimer, Yi-Fu Tuan, Edward Relph e David Lowenthal - e o conceito de espaço vivido, do francês Armand Frémont. Nota-se que esta dupla orientação aponta para a existência de uma instabilidade conceitual, que traz elementos da fenomenologia de Edmund Husserl, juntamente com conceitos inerentes à psicologia. Diante desta constatação, o artigo apresenta a contribuição dos geógrafos franceses Augustin Berque e André-Louis Sanguin, bem como dos geógrafos brasileiros Milton Santos e Werther Holzer, além da perspectiva analítica do sociólogo francês Alain Touraine e dos filósofos, também franceses, Jean-Paul Sartre e Jean-Marc Besse. O intuito é pensar o sujeito com vistas a atenuar as oscilações do conceito de mundo vivido quando este é posto frente à ideia de coletividade.
\end{abstract}

Palavras-chave: Geografia brasileira. Conceito de vivido. Tendência Humanista-Cultural. Sujeito e coletividade.

\section{THE LIFEWORLD IN BRAZILIAN GEOGRAPHY: ABOUT THE INSTABILITY OF A HUMANIST-CULTURAL CONCEPT IN THE EARLY $21^{\text {ST }}$ CENTURY}

\begin{abstract}
The construction of what is called in this work as the Humanist-Cultural Tendency of Brazilian Geography has been taking place. It is understood as a set of productions that absorbs plural perspectives in regard to methodical influences and theoretical landmarks in addition to facing the individual. The study is based on the analysis of contemporary Brazilian geographic production, more specifically those from the first decade of the 21st century, which use the notion of Lifeworld as a theoretical support, starting from the reading of Anglo-Saxon authors such as Anne Buttimer, Yi-Fu Tuan, Edward Relph and David Lowenthal to the concept of espace vécu by the Frenchman Armand Frémont. One notices that this double orientation points to the existence of conceptual instability, which brings elements of Edmund Husserl's phenomenology, together with concepts inherent to psychology. Given to this observation, the article brings the contribution of the French Geographers Augustin Berque and André-Louis Sanguin and the Brazilian geographers Milton Santos and Werther Holzer, in addition to the French sociologist Alain Touraine and the French philosophers, Jean-Paul Sartre and Jean-Marc Besse, so as to think the subject with a view to mitigate the oscillations of the concept of Lifeworld it is faced with the idea of collectivity.
\end{abstract}

Keywords: Brazilian Geography. Concept of Lifeworld. Humanist-Cultural Tendency. Subject and collectivity

\section{INTRODUÇÃO}

"A percepção é sempre um processo seletivo de apreensão. Se a realidade é apenas uma, cada pessoa a vê de forma diferenciada; dessa forma, a visão pelo homem das coisas materiais é sempre deformada." 
O presente trabalho propõe averiguar o advento da pluralidade de temas e métodos na geografia contemporânea e, de forma mais específica, explicitar as escolhas e os mecanismos de análise ao se conceber o conceito de vivido no âmbito do indivíduo. Problematiza-se, dessa forma, que geografia é esta que pretende pensar o real a partir da escala do indivíduo e, neste sentido, examina-se a dinâmica que se desdobrou no Brasil no início do século XXI, mais precisamente na primeira década do século, sendo estes os eixos centrais analíticos deste artigo.

Em meio à plêiade de influências e de marcos teóricos, é possível perceber uma constante fenomenológico-existencial que, apesar de não se constituir como uma escola de pensamento propriamente dita, usualmente se define como o fundamento do que vieram a ser a Geografia Humanista e a Geografia Cultural. Neste trabalho, busco compreender o que nomeio como tendência humanistacultural da geografia brasileira, a partir do conceito de vivido. A proposta é evidenciar uma tensão no interior desta tendência aqui apresentada, tensão esta que se expressa tendo, de um lado, alguns princípios da fenomenologia e suas interfaces existenciais e, de outro lado, a dimensão psicológica adotada a partir dos conceitos de percepção, afetividade, sensação e cognição. Detecta-se, neste movimento, um paralelismo de sentidos contrários, que, dessa forma, apesar de se encontrarem na mesma rota, estão em direções opostas, fazendo com que não se criem mecanismos teóricos que possam aglutinar e convergir para o mesmo ponto.

Nota-se que, no arcabouço epistemológico em disputa em torno da tendência humanista-cultural brasileira, vincula-se centralmente a noção de vivido, que flutua entre a interpretação do conceito de mundo vivido, alicerçada em leituras de pensadores anglo-saxões como Anne Buttimer, Yi-Fu Tuan, Edward Relph e David Lowenthal, e a noção de indivíduo que remete à psicologia piagetiana, que está na base do pensamento de Armand Frémont e de seu conceito de espaço vivido, cunhado em solo francês. Há, nesta empreita, a compreensão de indivíduo, fruto desta fonte multifacetada, que carrega um caráter somatório na composição dos elementos que forjam a ideia de sujeito. Nessa medida, o presente artigo lança luz sobre a diferença de natureza que há entre o sujeito empírico guardado à sua intimidade e o sujeito como coletividade.

Diante da constatação da instabilidade na propositura do conceito de vivido no Brasil, chamo a atenção para duas análises de filósofos empenhados em compreender as raízes constitutivas da fenomenologia. Aponto o que para Ernildo Stein se tornou o entrave deixado por Edmund Husserl, pai da fenomenologia contemporânea. Stein traz à tona a dificuldade apresentada na fenomenologia de Husserl em relação à ideia de vivido quando se quer buscar a universalidade, dilema este que é enfrentado pela geografia brasileira com a reprodução de algumas incongruências. Por outro lado, trago a contribuição de Jean-François Lyotard, que afirma a mathesis universalis no pensamento de Husserl para enfrentar as noções de contingente e singular que supostamente teriam deflagrado a fragilidade da fenomenologia. Sob essa perspectiva, o artigo assinala a necessidade de se orientarem as pesquisas para além do indivíduo datado e da dimensão psicológica de cada pessoa como fonte do saber geográfico em si.

Alinhado ao debate sobre o sujeito, inerente à questão do indivíduo posta pela tendência humanistacultural brasileira, o artigo traz a contribuição dos geógrafos franceses Augustin Berque e André-Louis Sanguin e dos geógrafos brasileiros Milton Santos e Werther Holzer, além das formulações do sociólogo francês Alain Touraine e dos filósofos, também franceses, Jean-Paul Sartre e Jean-Marc Besse. Apesar de partirem de lugares e interesses sensivelmente distintos, esses autores constituem no texto um arranjo no modo de pensar o sujeito com vistas a atenuar as oscilações do conceito de vivido quando este é posto frente à ideia de coletividade.

Em alguma medida, o trabalho adverte para uma interpretação incompleta da ideia de vivido que teria nutrido a geografia brasileira a partir da leitura de autores anglo-saxões, trazendo um recorte francês para evidenciar alternativas para o pesar do sujeito em meio ao processo de consolidação de um pensamento voltado ao humanismo na Geografia. O texto foi organizado em três movimentos: o primeiro traz uma discussão sobre as raízes do plural na ciência e o modo de ser da Geografia em relação a este acontecimento; o segundo averigua o conceito de vivido em suas duas versões trazidas à tona com a ideia de instabilidade, fruto do paralelismo de sentidos contrários; e o terceiro apresenta os limites e propõe um olhar viável para a tendência humanista-cultural brasileira pensar a dimensão do sujeito. 


\title{
O PLURAL, O INCERTO E A ESCALA NO INTERIOR DE UMA TENDÊNCIA EM CONSTRUÇÃO
}

O plural parece ter feito morada nas ciências humanas em fins do século $X X$, quando correntes de pensamento que ganharam força no pós-Segunda Guerra e, mais precisamente com a hecatombe existencial do fim da década de 1960, ${ }^{1}$ propuseram-se a rever a rigidez dos grandes sistemas filosóficos. A abertura para o plural, tanto na escolha dos temas quanto na variedade de métodos, passou por processos de idas e vindas e abriu o século XXI com maior aceitação ao redor do mundo. Há, por conseguinte, uma espécie de ganho de confiança entre os pesquisadores interessados em desestabilizar a ciência como concebida na modernidade e em propor hibridismos e fluidez.

O jogo de tensões ainda está em curso, e qualquer tentativa de ajuntamento dos caminhos epistemológicos de uma dada ciência torna-se tarefa árdua e com pouco fulcro, devido às diversas influências que participam deste cenário. No caso da Geografia, há, ainda, a particularidade de que, somente no fim da década de 1970, especificamente no ano de 1978, é que tivemos o início do que se convencionou chamar de movimento de renovação, quando tomou força o questionamento feito à Geografia de viés positivista/neopositivista pela crítica de linhagem marxista. $O$ fato é que o que poderia ter criado um edifício monolítico na renovação - ou seja, o marxismo - não se fez por inteiro, muito provavelmente pelo que Ruy Moreira, geógrafo de primeira hora do movimento, afirma em sua análise depois de passados dez anos:

\begin{abstract}
Descobre-se a historicidade do espaço, o fio da História entretanto permanecerá ignorado. O geógrafo descobre a História sem descobrir-lhe o fundamento mais simples. É possível falar da historicidade sem falar do sujeito do processo? A Geografia renovada diz que sim, e fornece a fórmula: basta que se fale da História mantendo seu sujeito "oculto por eclipse" (MOREIRA, 1992, p. 15).
\end{abstract}

Esse ocultamento do sujeito foi posto como uma das questões centrais no decorrer dos anos de sedimentação da Geografia Crítica e, apesar de não ter comovido de maneira densa os geógrafos que adotam o marxismo ortodoxo, não passa despercebido. Uma das formas mais marcantes do questionamento sobre a ausência do sujeito e do desdobramento da pluralidade se deram, em grande medida, quando as análises passaram a se debruçar sobre escalas que usualmente tratam os indivíduos como particularidade e o mundo na dimensão do vivido. O discurso se alicerça em aportes filosóficos e fundamentos científicos com extensa diversidade; sem dúvida, há também pitadas de ecletismo na elaboração do pensar geográfico neste início de século XXI. Refiro-me aqui não somente à consagrada nomenclatura dada à vertente humanista, mas também aos rótulos cultural, da percepção pós-moderna e, mais recentemente, decolonial. Não é possível reunir a produção desta plêiade geográfica dentro do que se convencionou chamar de corrente de pensamento propriamente dita; não há, e talvez não terá por deliberada vontade dos pesquisadores, um grau de nucleação suficientemente destacado. No caso da produção das reconhecidas Geografia Humanista e Geografia Cultural no Brasil e no mundo, ocorre um entrelaçamento de tal ordem que prefiro adotar o termo tendência humanista-cultural para me referir a este debate epistemológico em construção, e é sobre esta tendência que pretendo aprofundar as reflexões.

A análise voltada ao indivíduo, que se nota na produção geográfica desta tendência humanistacultural, não é apenas uma intenção de gradação dos estudos. Há noções particularizantes e singulares na construção de uma ideia de subjetividade, vinculadas ao indivíduo como objeto de pesquisa, que trazem à tona um trato idiossincrásico até então inédito para a Geografia moderna. Este contato com o indivíduo se faz a partir da utilização e validação de expressões comuns à psicologia; a absorção de conceitos como percepção, afetividade, sensação e cognição deflagra uma tentativa de guiar o pensamento geográfico rumo ao indivíduo não apenas como uma calibragem da escala geográfica, mas também como afirmação de outra dimensão do sujeito.

O modo como o indivíduo é visitado por grande parte da tendência humanista-cultural brasileira, ao menos na primeira década do século XXI, emula o comportamento em que o sujeito/pesquisador se viu envolvido a partir das descobertas da mecânica quântica do início do século XX. Diante do assombro contemporâneo - em cuja matriz originária situo o princípio da incerteza de Heisenberg, desenvolvido entre 1925 e 1927 -, inicia-se outro embaralhar das cartas nas ciências da natureza e

\footnotetext{
1 Aqui me refiro aos movimentos negro, feminista, ambientalista, hippie e, mesmo o maio de 1968 , em suas digressões políticas, comportamentais, filosóficas e culturais que, em conjunto tentaram colocar a história em ebulição e reviraram diversos modelos de sociedade já consolidados.
} 
que iria chegar a terrenos dominados pelas ciências humanas posteriormente. A partir de então, teríamos que conviver com a ideia de que, em nível atômico, não conseguimos medir sem que nossa intervenção impedisse a comunicação exata do objeto da medição. As inquietações promovidas pelas descobertas quânticas operaram nova forma de pensar o sujeito e o objeto ao questionarem as dualidades e as dicotomias tão caras às ciências naturais e também à Geografia moderna.

Defendo aqui que o pensamento que opera com base na incerteza, no fortuito e no aleatório, presentes nas profundezas do átomo, fez emergir algo distinto para as ciências humanas; o problema é que por diversas vezes este evento é reconhecido como a presença do pós-moderno na ciência. Quero ir por um caminho substancialmente diferente; proponho que, juntamente com a adoção das microrrealidades individuais como esfera do saber geográfico, que decorre desta relação sujeito e objeto "quântica", há também a afirmação do indivíduo em sua dimensão psicológica. O sujeito que pesquisa com os olhos voltados para o indivíduo, este geógrafo/sujeito, não trabalha em nome de uma redução analítica apenas, mas busca deflagrar um viver atípico no que se refere à ideia de integração já usual na Geografia. A partir da noção de "todo", característica do discurso do holismo, que também possui um viés quântico, almeja-se enfrentar os pares duais próprios à constituição da Geografia como ciência: natureza e homem, ambiente e sociedade, Geografia física e Geografia humana.

Trabalhar o saber geográfico pelas vias do conhecimento do indivíduo é, neste sentido, estimular um encontro com o lugar de vida; em síntese, é a integração entre o sujeito e o objeto circundante. $\mathrm{O}$ mundo experimentado por indivíduos entremeados pelas coisas - e aqui digo pelos lugares - em nível quântico é um só, e o incerto é seu modus operandi, um intercambiar entre o mundo macroscópico da vida e o mundo quântico. É o que Boaventura de Souza Santos, em suas análises sobre a ciência, afirma ao tratar da dinâmica epistêmica em sua interface com o mundo real. Nas palavras do próprio autor:

Enquanto a distinção entre sujeito e objeto é uma distinção epistemológica que, supostamente, tem consequências ônticas (realidade, mundo real), a distinção entre natureza e cultura/sociedade é, supostamente, uma distinção ôntica com consequências epistemológicas (SANTOS, 2000, p. 85).

A distinção entre sujeito e objeto, que está na base do pensamento cartesiano e figura como fundamento da moderna Geografia, ao ser questionada por esta inclinação à epistemológica quântica, promove quebra nesta dualidade e, de maneira viva defende o sentido de integração, característico desta visão holística. Cabe aqui ressaltar que não me refiro somente à tradicional contenda entre geografia física e geografia humana e suas diversas tentativas de integração que traz certos ares de utopia, mas trato dos estudos que recorrentemente se colocam como partidários de um pensamento integral que, para além da quebra da dualidade entre geografia física e geografia humana, buscam reposicionar o papel da ciência e do fazer do cientista/geógrafo.

Juntamente com o pensamento que ativa novos limites no debate entre sujeito e objeto impostos pela descoberta do quântico, observa-se, também, uma forte atenção às filosofias que priorizam a relação em si, estabelecida entre sujeito e objeto, não como polos distintos, ao modo cartesiano, nem como uma indistinta integração como advoga o holismo. Aqui, a fenomenologia e o existencialismo oferecem caminhos alternativos.

Neste encontro com o indivíduo abarcado por uma dimensão psicológica e sob a égide de uma integração que pretende fundar nova síntese geográfica é que se edifica a tendência humanistacultural. Este jogo de forças que há entre os sentidos inerentes à fenomenologia, de um lado, e aqueles vindos da psicologia, de outro, é vitalizado pela proximidade constante da noção de existência e da referida ideia de integração holística. E aqui reside a marca da crise da razão e do nível de integração e síntese que a Geografia nos dias atuais deveria costurar.

Como os alicerces da tendência humanista-cultural brasileira estão ainda em fase de elaboração, os aspectos reconhecidos como inerentes ao sujeito aparecem, muitas vezes, como pedaços mal acabados, ou como "cacos" de subjetividade, diluídos na dimensão psicológica de cada observador e de cada indivíduo observado. Numa reação intrigante, os cacos, que são reconhecidos como expressões concretas da realidade, são lançados ao mundo como restauradores da integridade e da unidade físico-cultural.

Aqui me valho da ideia de "cacos" apresentada por Ruy Moreira, em O discurso do avesso, de 1987, quando ele se referia à falta de compromisso categorial do discurso fragmentário que comprometeria 
a tentativa de síntese geográfica. Moreira afirma que "como a Geografia opera acategorialmente, sua síntese, para exemplificar, tende a ser uma reunião de cacos, feita, aqui e ali, com maior e menor habilidade e inteligência" (MOREIRA, 1987, p. 21). A maneira como a Geografia promove sínteses e a forma como, a partir destas sínteses, propõe interpretação do real, de forma particular e distinta das outras ciências, traz para Moreira três graves consequências. A primeira delas seria "uma visão caótica de conjunto"; a segunda, uma "frouxidão de identidade"; e a terceira estaria no fato de ser a Geografia "um campo elástico", podendo, neste caso, caber tudo no espectro de estudo geográfico.

Esta ingerência conceitual, metódica e categorial que aponta Moreira é também detectada no processo de consolidação da tendência humanista-cultural brasileira, pois, para além dos conceitos oriundos das ciências sociais, da filosofia e das ciências da natureza, agregam-se os conceitos vindos da psicologia numa alusão à atividade "mental e sensorial" de cada indivíduo. Esta proposta de reinventar o modo geográfico de apreensão do real é um convite ao enfrentamento de novas sínteses, agora fundadas na intimidade das pessoas. Neste sentido, em virtude de se voltar para os indivíduos em seus universos restritos, estabelece-se com o real uma relação ambígua, e o pesquisador se "integra" ao indivíduo pesquisado, pois é esta identificação entre sujeito e objeto que alimenta a tendência. Isso se dá porque os indivíduos pesquisados não participam necessariamente dos conjuntos interpretativos dos geógrafos que ali se põem a atuar. Neste caso, o desafio é a validade de se consagrar um confundir/fundir do sujeito que pesquisa no objeto pesquisado, e até que ponto não se opera apenas um ajuntamento de "cacos"? Seriam pedaços encontrados nos indivíduos, pedaços de sentimento, pedaços de compreensão, que levam a uma ilusão do real. Um real que é buscado no olhar sensível daquele que passeia. Um real que, em larga escala, reduz-se à intimidade de cada pessoa. É neste despejamento da pessoa/pesquisador/sujeito no mundo que se espera encontrar o sentido mais legítimo da realidade, uma tradução do imediato/cotidiano vivido pelos indivíduos.

\section{ESPAÇO VIVIDO/MUNDO VIVIDO E O TRATO CONCEITUAL EM SOLO BRASILEIRO}

No prefácio à segunda edição de seu La région espace vecú, publicado em 1976 e redigido em 1974, Armand Frémont afirma que sua obra foi escrita num contexto pós-Maio de 1968; portanto, em momento de grande efervescência na academia. As criações das revistas L'Espace Géografique, de Roger Brunet em 1972, Espaces Temps, de Jacques Levy em 1975, além do lançamento de "uma bomba", nas palavras de Frémont, do livro A geografia - isso serve em primeiro lugar para fazer a guerra, de Yves Lacoste em 1976, evidenciavam que "a Geografia clássica, ou seja, a escola francesa, inspirada em Vidal de La Blache, estava então, é verdade, em um impasse tanto teórico quanto prático, senão político" (FRÉMONT, 1999, p. 7). ${ }^{2}$ Em meio aos posicionamentos ideológicos entre os pesquisadores chamados antigos e os novos pesquisadores interessados em outra Geografia, surge sua obra, que trazia o conceito de espaço vivido. Naquele momento, ocorre o deslocamento do interesse pelo conceito de região da maneira clássica e o ganho de solidez do que ele chamou de "obra infindável" do teórico e filósofo da Geografia contemporânea, Paul Claval.

Este prefácio escrito por Frémont chama a atenção por trazer à baila a noção de que a produção da Geografia Crítica Marxista ocorre no mesmo momento histórico da construção do que posteriormente ficou reconhecida como Geografia Cultural Renovada, algo que põe em xeque interpretações usuais por parte da Geografia brasileira que viam um monolitismo marxista no Movimento de Renovação da década de 1970, como também percebe Ruy Moreira. Ademais, todo esse acontecimento em solo francês ocorre num mesmo levante temporal do lançamento de textos basilares do que viria a ser a chamada Geografia Humanística, ${ }^{3}$ de referência anglo-saxônica, que ofereceria $\circ$ norte

\footnotetext{
${ }^{2}$ La géographie classique, c'est-à-dire, l' « école française », inpirée de Vidal de La Blache, était alors, il est vrais, dans une impase aussi bien théorique que practique, si ce n'est politique.

3 Sobre a diferenciação dos termos Humanista e Humanística, há uma conclusão bem interessante no trabalho
de Werther Holzer. O autor afirma que "[...] no inglês e no português, podemos utilizar tanto Humanista quanto
Humanística". No entanto, em português, o primeiro é adjetivo comum de dois gêneros, o segundo não. Es-
colhemos o primeiro, pois associa-se imediatamente ao substantivo "Humanista", que é associado, em seguida,
ao humanismo filosófico e ao estudo das humanidades, além de ser de emprego muito mais antigo em nosso
idioma. O caráter substantivo do termo "Humanista" é muito importante, pois indica uma corrente da Geografia
nitidamente diferenciada de uma Geografia positivista e estruturalista (e não podemos falar Geografia
positivística ou estruturalística). HOLZER, Werther. A Geografia humanista - sua trajetória de 1950 a 1990.
} 
epistemológico para o pensamento sobre o mundo da vida empreendido por parte da Geografia brasileira, que também havia participado da crítica à quantificação e ao positivismo. Vale lembrar que, entre os anos 1973 e 1976, foram lançados em territórios de língua inglesa a tese de Edward Relph, defendida em 1973, e publicada em 1976, com o título de Place and Placeness; a obra Topofilia, de Yi-Fu Tuan, publicada em 1974; além do artigo de Anne Buttimer "Aprendendo o dinamismo do mundo vivido", publicado em 1976. Não se pode esquecer que, em 1982, sob a organização de Antonio Christofoletti, publica-se o livro Perspectivas da Geografia, com textos fundamentalmente de geógrafos franceses e anglo-saxões, contando com o artigo de Buttimer citado acima, além de "Geografia humanística", de Tuan, e "Geografia, experiência e imaginação: em direção a uma epistemologia geográfica", de David Lowenthal, que, mesmo tendo sido escrito originalmente em 1960, traz o pluralismo que marcaria seu trabalho posterior e que também está presente na proposta de Frémont:

É dentro deste contexto que eu escrevi Região, espaço vivido. Eu tentava conciliar o uso de conceitos clássicos da Geografia francesa, a região, mas também a combinação geográfica, num aporte considerável de ciências humanas e sociais, particularmente da psicologia, da antropologia, da sociologia, como de análise econômica explicitamente reconhecida (FRÉMONT, 1999, p. 9). ${ }^{4}$

Chamo atenção para o fato de Armand Frémont deixar explícito que suas reflexões possuem interface com a psicologia - neste caso, mormente a psicologia genética de Jean Piaget - e estão mais próximas de Vidal de La Blache do que de qualquer influência fenomenológica. A articulação entre o mundo da vida com absorção psicológica e outros campos do saber expõe o debate sobre o nível de acabamento que teriam as sínteses que a Geografia realiza. O fato é que a síntese proposta por Frémont não confere olhar fenomenológico exatamente pelo modo como ele afirma seu conceito de vivido; ao buscá-lo em Piaget, ele ativa a percepção de crianças, adultos e idosos numa leitura do espaço. No caso das crianças, por exemplo, Frémont reconhece que os estágios de desenvolvimentos cognitivos da teoria piagetiana possibilitam pensar espaços vividos que assumiriam as próprias características do estágio em que a criança se encontra. ${ }^{5}$ Poder-se-ia inferir que a aproximação com a psicologia, que é expressa na obra de Frémont, racharia em duas perspectivas a chamada Geografia Humanista; no entanto, defendo aqui que a adoção dos mecanismos de reflexão advindos da teoria piagetiana não confronta diretamente a interpretação que a tendência humanistacultural fez desta questão. No Brasil, as discussões que têm como base os geógrafos humanistas anglo-saxões não se deram com clara diferenciação entre os conceitos de espaço vivido, de Armand Frémont, e de mundo vivido, de Anne Buttimer, mesmo que a autora irlandesa afirmasse ter sua base na fenomenologia e Frémont se aproximasse da psicologia. André-Louis Sanguin, acerca desta noção de vivido, afirma que:

Sob o vocábulo espaço vivido, uma corrente de pensamento apareceu gradualmente no fim da década de sessenta. Muito curiosamente, esta corrente se aproxima à abordagem humanista anglo-saxônica, mas nenhuma passarela foi estabelecida entre as duas escolas, e, de uma maneira explícita e oficial, a escola francesa não adotou a perspectiva fenomenológica e existencialista. No entanto, ela utiliza a mesma linguagem que os humanistas anglo-fônicos e os temas das suas contribuições são facilmente comparáveis àquelas do outro lado do Atlântico (SANGUIN, 1981, p. 574). ${ }^{6}$

1992. Dissertação (Mestrado em Geografia) - Instituto de Geociências, Universidade Federal do Rio de Janeiro, Rio de Janeiro.

4 "C'est dans ce contexte que j'ai écrit La Region et espace vecú. J'essayais d'y conciliaer le recours à des notions classiques de la géographie française, la région mais aussi la combination géographique, à l'apport considérable des sciences humaines et sociales, particulièrment de la psychologie, de l'antropologie, de la sociologie ainsi que de l'analyse économique explicitament reconnue."

${ }^{5}$ Frémont aborda esta questão se referindo não somente a Jean Piaget, mas também a partir de $\mathrm{H}$. Wallon e J. Guillouet.

6 "Sous le vocable d'espace vecú, un courant de pensée est apparu graduellement à la fin de la décennie soixante. Fort curieusement, ce courant rejoint l'approche humaniste anglo-saxonne mais aucune passarelle n'a été établie entre les deux écoles et, d'une façon explicite et oficielle, l'école française n'a pas adopté la perspective phénoménologiste existencialiste. Cependant, elle utilise le même langage que celui des humaniste anglophones et les thémes de ses contribuitions se comparent aisément à ceux d'Outre Atlantique." 
As congruências entre as discussões dos anglo-saxões e dos franceses sobre o conceito que é reconhecido como vivido conduzem, em boa medida, o pensar da tendência humanista-cultural brasileira. Aqui do Atlântico Sul, promoveu-se uma quase amálgama conceitual. O empréstimo ligeiro que a Geografia tomou, da análise do vivido, parece agudizar os recortes teóricos essenciais que versam sobre as dificuldades enfrentadas pelos próprios geógrafos no trabalho com a fenomenologia. Werther Holzer afirma, diante disso, que:

O fato é que as dificuldades, talvez na compreensão, mas certamente na aplicação do método, levariam a propostas de sua utilização de modo implícito (RELPH, 1976, nota 7, p. 7; TUAN, 1976), ou a propostas de descarte de determinadas fenomenologias, a pura de Husserl, ou a hermenêutica, de Ricoeur, com a manutenção apenas do "espírito" da filosofia, que estaria contido no conceito de "Lebenswelt", a vida cotidiana (BUTTIMER 1976), que os geógrafos franceses, sem tantas preocupações de delimitações teórico-conceituais, souberam muito bem estudar a partir do "espace vecú" (HOLZER, 2003, p. 115).

É nítido que, em solo brasileiro, as possíveis diferenças existentes entre as abordagens das correntes francesa e anglo-saxônica foram arrefecidas, principalmente pelo fato de a adoção do conceito de vivido não ter tido base fenomenológica propriamente dita, como afirma Holzer, e, acima de tudo, pelo fato de que, nas figuras de Paul Claval e sua Geografia Cultural, em primeiro plano, e de Armand Frémont, em segundo, é que foi feita a leitura brasileira mais densa dos autores franceses. Assim, aliando-se o vivido anglo-saxão - apenas como uma referência fenomenológica, e não como categoria de análise - a traços de subjetividade, atrelados à esfera psicológica, como há em Frémont, pode-se costurar a base epistemológica anglo-saxã dessa tendência. Ressalto, ainda, que a obra L'homme et la terre, de 1952, de Éric Dardel, ${ }^{7}$ é mais consagrada do que a própria obra La région espace vecú, de Frémont, nos debates da tendência humanista-cultural brasileira no início do século $\mathrm{XXI}$.

A proximidade da tendência humanista-cultural brasileira em relação aos pensadores anglo-saxões, demonstrada por diversos artigos publicados na primeira década do século XXI, evidencia um enigma acerca do entendimento das raízes teóricas e metódicas da referida produção ao tratar do vivido e, em última instância, do indivíduo e do cotidiano. No escopo diverso da tendência humanista-cultural brasileira, pela via anglo-saxã, centralmente aparece Yi-Fu-Tuan, a partir da leitura fortemente influenciada pelo conceito de topofilia, e seu correlato topofobia. ${ }^{8}$ Sua proposta de Geografia Humanística é incorporada aos estudos do cotidiano, calcados na percepção e na afetividade (SERPA, 2007; MACIEL, 2002; OLIVEIRA, 2007; GRATÃO, 2007; AMORIN FILHO, 1999), assim como sua contribuição ao pensar sobre objetividade e subjetividade (KOZEL, 2010). Em Tuan, buscase a afirmação da centralidade do conceito de lugar (HOLZER, 2003) e a possibilidade de pensar a família e o lar (OLIVEIRA e CAVALCANTE, 2009; COLESANTI, 2007). De forma geral, os pensadores brasileiros veem em Tuan a condição primordial para aproximar a Geografia de noções mais corriqueiras da vida cotidiana, algo bastante explícito na ideia de espaço vivido de Frémont.

Seguindo o ideário humanista que há em Yi Fu Tuan, Anne Buttimer é considerada como referência de mesma amplitude. Os autores brasileiros confirmam o discurso da autora no trato do mundo subjetivo e preenchido de vida - o mundo vivido, em síntese conceitual (KOZEL, 2010; COLESANTI, 2007, AMORIN FILHO, 1999; OLIVEIRA, 2007). Com Buttimer, é posto o desafio de pensar a existência de cada indivíduo em sua vivência particular (NOGUEIRA, 2005). Outra contribuição endereçada à Anne Buttimer é a sua atenção à maneira clássica de se fazerem as monografias regionais, afirmando ser esta atitude científica uma possibilidade atual de interpretação geográfica: "Em outros termos, como diz Buttimer, trata-se de reintroduzir, através do humanismo, os conceitos de base da Geografia Clássica, como os de gênero de vida" (GOMES, 2003, p. 313). Algo que também não teria sido abandonado por completo por Frémont.

\footnotetext{
${ }^{7}$ No presente texto optei por não trazer as questões inerentes ao trabalho com a obra de Dardel que certamente é muito expressivo na geografia brasileira. Esta decisão se deu pelo fato de compreender que um texto que aborde a contribuição de Dardel teria que partir de outras questões que não se colocam como centrais aqui. É preciso dizer também que se trata de uma obra de 1952 e que teria sido relida em outro contexto que pretendo discutir de forma mais detida em outro texto. Faz parte do risco das escolhas.

${ }^{8}$ Os conceitos de topofobia e topofilia são claras aproximações à noção de sentimento de pertencimento, de um lado, e sentimento de aversão, medo de outro em relação ao lugar. Yi Fu Tuan vai trabalhar esses conceitos em sua obra Topofilia: um estudo da percepção, atitudes e valores do meio ambiente.
} 
Em Edward Relph, ${ }^{9}$ além de se depositar a responsabilidade de levar a obra L'homme et la terre, de Dardel, e sua geographicité 10 para o solo estadunidense, tem-se conferido o mérito, juntamente com Tuan e Buttimer, de propor que "o lugar passa a ser entendido não apenas como localização, mas como fenômeno experenciado pelos homens que nele vivem" (NOGUEIRA, 2007, p. 5), numa clara alusão à escala de estudo geográfico e aos limites da localização ou posição como "condição necessária ou suficiente para constituir os lugares" (COLESANTI, 2007, p. 10). A lista de geógrafos dessa vertente anglo-saxônica pode ser engrossada com outros diversos autores, ${ }^{11}$ para os limites da investida momentânea, vale observar algumas ressalvas no que se refere a determinados pontos centrais da corrente humanista anglo-saxônica.

O geógrafo inglês Denis Cosgrove é lembrado como marxista (MACIEL, 2002) e também por uma sugerida aproximação pós-moderna (ALMEIDA, 2008), além de seu trabalho com cartas cognitivas (SERPA, 2007). Mesmo com certas divergências na tentativa de posicionar este autor, há uma concordância de que ele apontaria certos limites para o entendimento do mundo pela via da percepção. Outro autor importante é David Lowenthal, lembrado em menor grau pela Geografia brasileira, mas tido como um elemento de força aos pensamentos de Tuan e Buttimer, trazendo também uma contribuição importante para pensar a "relação entre o mundo exterior e as imagens nas cabeças das pessoas" (OLIVEIRA e CAVALCANTE, 2009, p. 47). Outros geógrafos brasileiros poderiam figurar neste trabalho, entretanto minha preocupação não está voltada para os estudos aplicados; cito alguns artigos que de maneira peremptória se põem como interessados pelos limites epistemológicos do saber.

Resumidamente, seguem em curso duas agitações de maneira muito clara: primeiramente, a inspiração anglo-saxã que teria atingido a Geografia brasileira, com aludida sustentação fenomenológica atribuída aos trabalhos de Anne Buttimer, Yi-Fu-Tuan, Edward Relph e David Lowenthal, que majoritariamente catalisou o encontro com o vivido. Em segundo lugar, a despeito deste alinhamento anglo-saxão, a noção de indivíduo remete a uma subjetividade que, na psicologia piagetiana, trata-se da esfera da vida cotidiana, e que está na base do pensamento de Frémont. Diante disso, o movimento de acomodação epistemológica da tendência humanista-cultural brasileira carece de pensar o conflito entre o indivíduo e o coletivo social; o dilema que se impõe é que, ao levar este entendimento de vivido para uma dimensão psicológica, opta-se por tratar cada objeto/indivíduo com uma interpretação particular, diferentemente do modo de se posicionar o sujeito/indivíduo em relação ao mundo vivido tratado por Edmund Husserl.

Há aqui um paralelismo de sentidos contrários gerador de instabilidade, ou seja, o modo em que o sujeito aparece no interior das discussões da tendência humanista-cultural percorre de forma paralela a apreensão do sujeito na fenomenologia; porém, em outra direção, sem promover um encontro durável. Dizendo de outra forma, juntaram-se os conceitos como uma espécie de amálgama nas discussões e, após esta junção, eles seguem direções exatamente opostas, guardando, assim, apenas o encontro, mas sem o caminhar com a noção de vivido da fenomenologia. Neste caso, a Geografia reproduziria o que Ernildo Stein aponta como sendo a maior pendência deixada pela fenomenologia. Stein assim descreve o conflito:

Essa questão, a fenomenologia enfrentou e não resolveu. De certo modo, nasceu disso o fracasso da fenomenologia, pois o mundo vivido é sempre o mundo vivido de cada um singularmente considerado. Portanto, as experiências não poderiam ser remetidas a um mundo vivido como comum coletivo (STEIN, 2004, p. 26).

A provocação apresentada por Stein não é branda. Caso sua interpretação esteja correta, cairia por terra a estrutura explicativa que sustenta a fenomenologia por inteiro; afinal, a intenção de Husserl, e

\footnotetext{
${ }^{9}$ Edward Relph, apesar de ser canadense, foi significativamente influenciado pela Geografia estadunidense e escreve em inglês. Assim, preferi mantê-lo como representante da corrente anglo-saxônica aqui definida.

10 Apenas para corroborar com a nota logo acima, a ideia de geographicité de Dardel carrega uma carga simbólica muito marcante e não caberia aqui sobrevoar o conceito apenas, há em Dardel um desejo de abarcar uma totalidade humana numa espécie de fusão com a terra que de fato não se enquadra exatamente na leitura e na discussão que pretendo fazer sobre o conceito de vivido, mesmo que a noção de afetividade seja tão expressiva em Dardel.

11 Aparecem, também, nos textos dos geógrafos brasileiros, como representantes da aproximação à subjetividade, os autores Nicholas Entrikin, Leonard Guelke, David Ley, Marwyn Samuels, Douglas Pocock e outros.
} 
da fenomenologia advinda dele, é exatamente apontar para o universal. O rigor pretendido por Husserl não permitiria tal investida rumo ao particular guardado em cada indivíduo em suas vivências psicológicas, pois a empreitada do filósofo alemão, assim como Descartes, era conhecer o mundo e elucidar o modo como o processo de conhecer se põe. Jean-François Lyotard, em A fenomenologia, afirma que "o anseio cartesiano de uma mathesis universalis renasce em Husserl" (LYOTARD, 1999, p. 10). É sabido que, na esteira cartesiana, Husserl também se mostra desconfiado no que toca aos sentidos - no caso, sentidos que se referem aos indivíduos em sua finitude. $O$ acontecer aos sentidos é, por natureza, múltiplo, e a multiplicidade é própria do mundo empírico, algo que a fenomenologia pretende superar. Perceber, psicologicamente, o acontecer múltiplo e tê-lo como conhecimento do real, seria aceitar uma dada temporalidade característica do mundo empírico que não se estende de maneira direta ao sujeito. O sujeito não se reduz ao viver empírico. Ele é mais que isso. Ele aponta para o universal e o necessário inerente ao ser. Para Husserl, o encontro inevitável com o mundo precisa ser balizado pela sua conhecida redução eidética, que procura "ver" o objeto em sua durabilidade maior, em sua permanência intensa. É a decretada redução "que conduce del fenómeno psicológico a la pura esencia...” (HUSSERL, 1949, p. 10). Há neste pensamento de Husserl uma resistência em relação à aceitação da ideia de que o fenômeno em sua dimensão psicológica, por si mesmo, já estivesse apontado para o universal e necessário.

No capítulo II da primeira sessão do livro Ideias relativas a uma fenomenologia pura e uma fenomenologia filosófica, intitulado "As essências", Husserl dedica-se a expor o que ele adjetiva como "errôneas interpretações naturalistas". Neste capítulo, o autor deixa explícito que tanto empirismo quanto idealismo cometeram erros ao lidarem com a experiência. Para Husserl, o erro dos empiristas estaria em não pressupor que "a experiência direta daria apenas, em efeito, coisas e casos singulares, nunca universais"12 (HUSSERL, 1949, p. 51), e o erro dos idealistas seria o de terem colocado no lugar da experiência direta dos sentidos uma espécie de "sentimentos teoricamente inventados" (HUSSERL, 1949, p. 53). Corroborando isso, pode-se dizer que propor conhecer o mundo em sua complexidade múltipla, a partir dos sentidos individuais extremamente particulares, é constatar o equívoco de se buscar conhecimento no mundo em separado, naquilo que a sensação e a percepção escolhem como verdade e põem como representação empírica desse próprio mundo.

Sob essa perspectiva, a instância humana de onde brotam os sentidos é um receptáculo de informações do mundo vivido individualmente. Não há conhecimento das essências, no movimento operado pelo vivente individual e empírico, quando este direciona ao mundo. A carga de entendimentos advinda de uma experiência sensorial, notoriamente preenchida de dados psicológicos, não alcança a coisa em si, nem a verdade nem a permanência, seja ela como experiência direta ou como sentimentos que se dariam como uma criação teórica. Neste sentido, a experiência não sustenta o conhecimento, pois sempre fornecerá apenas "o contingente e o singular" (LYOTARD, 1999, p. 16). O mundo percebido pelos sentidos é, portanto, o objeto captado como real pelo sujeito na perspectiva empirista. Como lembra Lyotard, um objeto em sua mais rasa possibilidade. No inatismo de Descartes, a coisa que pensa, diferentemente, recebe o mundo como enganação e tenta, através da cadeia das razões, buscar o real. Entre o empirismo e o inatismo, uma avenida de possibilidades se abre. É nesta célebre contenda filosófica que o pensamento de Husserl se insere, e sua fenomenologia não se furta de enfrentar tal conflito. É sobre este mesmo terreno espinhoso que brotou a tendência humanista-cultural brasileira, e o conflito se põe de maneira incontornável; não é possível desconsiderar a disposição radical de questionamento do empírico como fonte do real se se almeja a um alinhamento com o pensamento fenomenológico de Husserl.

\section{EXTRAPOLANDO A CONDIÇÃO INDIVIDUAL NA FORMULAÇÃO DO VIVIDO EM GEOGRAFIA}

A Geografia, como ciência que se liga à terra e aos lugares, ao se colocar como investigadora do sujeito, terá que se opor ao indivíduo empírico e particularizado, sob pena de se embaralhar entre a noção de vivido fenomenológica e noção de vivido psicológica. A empreitada terá que promover escolhas no trato da vida, do indivíduo, dos lugares e das paisagens que envolvem a dinâmica da sociedade e da cultura; caso contrário, não se fará outra coisa, senão uma síntese mal acabada sobre o vivido.

12 "La experiencia directa sólo da, em efecto, cosas e casos singulares, nunca universales; pero esto no basta." 
Neste ponto, Carl Sauer, nome central do que se convencionou chamar de Geografia Cultural Tradicional, evidencia algo intrigante para pensar esta tentativa de conceber a subjetividade quebradiça como uma unidade geográfica. Sauer afirma que sua paisagem não é singularizada a ponto de ganhar significado tão específico que seja entregue para um indivíduo apenas. "No sentido aqui empregado, a paisagem não é simplesmente uma cena real vista por um observador. A paisagem geográfica é uma generalização derivada da observação de cenas individuais" (SAUER, 2004, p. 24). Destrinchando um pouco mais seu método de trabalho, observa-se que as ações individuais que estão na base do fazer geográfico podem ser constituidoras de uma descrição reconhecida como geográfica, tendo "sempre em mente o genérico", e, para finalização do processo, deve-se proceder "por comparação" (SAUER, 2004, p. 24). O limite parece estar na generalização e, como Sauer, de fato, reifica seu conceito de cultura (OLIVEIRA e CAVALCANTE, 2009), certamente seu conceito de paisagem possui também traços reificados; ao coisificar a paisagem, ele a torna produto de uma adição de observações individuais. Trago aqui Carl Sauer exatamente para clarear que a proposta de se somarem observações individuais, derivando até se alcançarem generalizações, demonstra tão somente a distância do pensamento de Carl Sauer em relação à abordagem fenomenológica. Uma das maiores lutas de Husserl foi, sem dúvida, contra certos modos de se fazer psicologia, que em sua visão estariam essencialmente calcados no empírico e nos moldes de pensar das ciências da natureza.

O psicologismo, diz Husserl, não consegue resolver o problema fundamental da teoria do conhecimento, ou seja, o problema de como é possível alcançar a objetividade; ou, em outros termos, como é possível que o sujeito cognoscente alcance, com certeza e evidência, uma realidade que lhe é exterior e cuja existência é heterogenia à sua (CHAUÍ, 1996, p. 6).

O limite da "Morfologia da paisagem", em Sauer, é apontado pela leitura da cultura realizada no interior da tendência humanista-cultural brasileira, que, em conjunto, propõe ampliar o conceito de cultura exatamente por perceber que "a cultura parecia funcionar através das pessoas para alcançar fins dos quais elas estavam vagamente cientes" (COSGROVE, 2004, p. 101). Essa visão é compartilhada pela tendência francesa da Geografia Cultural, sobretudo em Paul Claval, sendo um norte para a tendência humanista-cultural brasileira. Para Claval, na Geografia Cultural de Sauer, "a cultura é apreendida [...] em suas manifestações mais materiais: mesmo que Sauer entenda que ela comporte aspectos sociais e afetivos, ele parece ignorá-los"13 (CLAVAL, 2004, p. 100).

$\mathrm{Na}$ renovação da Geografia Cultural, seja pelo viés estadunidense ou pela proposta francesa, a notoriedade concedida à cultura se daria numa tentativa de se extrapolar o empírico. Entretanto, aspectos psicológicos, como no caso da afetividade, muitas vezes são tratados de maneira a serem apreendidos de forma representável/quantificável/qualificável; sendo assim, a tensão entre a pessoa em si e o sujeito não é resolvida. No artigo "A Geografia Cultural no Brasil", escrito por Roberto Lobato Corrêa e Zeny Rosendahl, fundadores do NEPEC (Núcleo de Estudos e Pesquisas sobre Espaço e Cultura), principal Núcleo de Estudos e Pesquisas em Geografia Cultural no Brasil, os autores afirmam que há uma Geografia Cultural implantada no país:

Como tal entende-se aquelas geografias de matriz saueriana, influenciada pela denominada nova geografia cultural e pelo "approche culturel" de Claval. A sua implantação gerou polêmicas pois, afinal, o que é visto como novo pode desafiar o establishment geográfico. No entanto, os adeptos da geografia cultural brasileira são, por definição, adeptos de uma heterotopia geográfica, sem a ascendência de nenhum grupo (CORREA e ROSENDAHL, 2005, p. 98).

Não é necessária uma larga pesquisa para se notar que, em virtude desta heterotopia há inserção de diversos modos de se conceber os sujeitos; entre os modos de apreensão dos sujeitos, de maneira expressiva, trabalha-se com indivíduos empiricamente observados e datados. E mais, o olhar empírico se mantém de forma mais evidente nos trabalhos que pretendem "aplicar" uma metodologia reconhecida como de cunho humanista-cultural. Me refiro aqui à quantidade de estudos que elegem um pequeno grupo, muitas vezes reduzidos a menos de uma dezena de indivíduos, para servirem de objetos/sujeitos a serem investigados, situação científica que atenderia algumas ciências específicas, como a própria psicologia e também a antropologia, por exemplo, mas para a Geografia é necessário realizar ajustes bem certeiros. Parto da convicção de que se a Geografia é uma ciência que prima por

13 "La culture est saisie ici dans sés manifestations les plus matérielles: même si Sauer sait qu'elle comporte des aspects sociaux et afectifs, il fait semblant de les ignorer." 
uma análise da sociedade e que se desdobra por categorias como lugar, espaço e território, será no mínimo necessário ampliarmos nossos trabalhos de campo para uma atitude etnográfica ou algo semelhante quando se pretende direcionar as pesquisas à escala do indivíduo.

Sem querer entrar numa exemplificação enfadonha, pouco elucidativa, nota-se que há uma contenção das pesquisas geográficas nos estudos que elegem um determinado grupo residente em um bairro, ou frequentadores de um Shopping Center, ou ainda sobre uma família de uma determinada comunidade ou alguns pescadores de uma vila ${ }^{14}$. Sinalizo para a visibilidade do fenômeno em si, ou seja, aquele observado pelo indivíduo que pesquisa através de seus próprios sentidos; mais precisamente trato tão somente dos trabalhos que, ao escolher um grupo ou um lugar a ser estudado, fazem-no de forma a buscar na própria experiência individual do objeto pesquisado os elementos que confeririam os mecanismos de interpretação do real coletivo. Ao se debruçarem sobre o pensar e o dizer da pessoa empiricamente percebida, tais estudos almejam extrair deste contato pessoalizado um constructo geográfico. Na busca por mais rigor nas análises que se voltam aos indivíduos, fartam-se de entrevistas e questionários para propor alguns padrões que norteiem o olhar que viabiliza a transposição da dimensão do indivíduo psicológico; e, nesses casos, muitos indivíduos, para a sociedade e a cultura. Pode-se afirmar que temos, assim, outra Geografia, interessada em diluir o indivíduo em seu viver cotidiano imediato. Mais que isso, o sujeito que pesquisa se despe de qualquer universalidade rumo ao desejo de encontro com o sujeito pesquisado. Parece haver uma reintrodução antropológica na Geografia, e tal acontecimento não seria um equívoco; entretanto, as ferramentas e as técnicas geográficas precisariam de renovação. Se o objetivo é adentrar as casas das pessoas e atingir a sensação, a percepção e a emoção na sua relação mais íntima que cada indivíduo trava consigo mesmo e com o outro, certamente será vital o aumento significativo do tempo de trabalho de campo, e inevitavelmente seria através de uma etnografia geográfica que isto se daria.

Fundamentalmente, não está em gestação outra antropogeografia, ou algo que o valha; talvez uma psicogeografia, mas ainda incipiente no que tange ao pensar social e às especificidades que conferem à Geografia, como ciência moderna, um estatuto singular de saberes e práticas. A inovação pretendida pela tendência humanista-cultural está articulada à tentativa de imprimir no conceito de sociedade uma instância subjetiva gestada na escala do indivíduo. Na aproximação com a subjetividade pormenorizada em estados psicológicos como a sensação, a percepção, a cognição e a afetividade, há implícita a interpretação de que a modernidade seria um período que tivesse se constituído sobre a derrota do sujeito. Nesse aspecto, ao elaborar sua crítica à modernidade, Alain Touraine faz uma bela síntese desses tempos de crise e de desesperança na razão que se configura o debate atual e se faz presente no pensamento geográfico contemporâneo:

Durante muito tempo, a modernidade foi apenas definida pela eficácia da racionalidade instrumental, a dona do mundo que se tornou possível pela ciência e a técnica. Esta visão racionalista não deve ser rejeitada de forma alguma, porque ela é a arma mais poderosa contra todos os holismos, todos os totalitarismos e todos os integrismos. Mas ela não dá uma ideia completa da modernidade; esconde a metade: a emergência do sujeito humano como liberdade e como criação (TOURAINE, 1999, p. 218).

Estruturado na emergência do sujeito, portanto, também se fez e se consolidou o pensar moderno. A razão universalista como desbravadora do mundo só foi possível graças à inteligibilidade do sujeito, primeiramente como libertação das amarras das verdades divinas e, posteriormente, como expressão relacional com o mundo. Touraine ainda afirma estar em curso uma falsa contradição posta na contemporaneidade, para o autor:

Fingir que uma nação ou que uma categoria social tem que escolher entre uma modernidade universalista e destruidora e a preservação de uma diferença cultural/absoluta é uma mentira grosseira demais para não encobrir interesses e estratégia de dominação (TOURAINE, 1999, p. 218).

\footnotetext{
14 Penso não ser necessário citar o quantitativo ou nomes neste momento, por entender que não se trata de um grupo específico de geógrafos. Vejo na Geografia uma constante em relação à realização de entrevistas com grupos de indivíduos e também aplicação de questionários para um percentual de pessoas envolvidas com uma realidade que se quer estudar. Um olhar mais detido para os anais dos eventos de Geografia Humana, os Congressos Nacionais e os Encontros da ANPEGE, pode oferecer um escopo mais fiel sobre esta afirmação.
} 
As ciências humanas, que buscam lapidar o pensar sobre o social e que historicamente se viram envolvidas com as angústias do sujeito, são chamadas para este diálogo com a modernidade. A Geografia é impelida a protagonizar de forma visionária o embate; afinal, desde seu surgimento entre viajantes e cartógrafos, já se debruçara sobre as escalas de análises tão marcantes no pensamento moderno. Além disso, as dualidades expressas não só na relação sujeito e objeto, mas também entre a natureza e homem, entre o geral e o particular, devem ser revisitadas pela Geografia. É exatamente nesta arena de debates que a tendência humanista-cultural se encontra, e será no trato ao indivíduo com maior ou menor capacidade de ilustrar o sujeito como coletividade que gravará sua importância. Nesta trilha elucidativa, os limites são impostos, e extrapolar esta condição analítica íntima de indivíduo é uma exigência para a consolidação desta tendência no Brasil. Não se pode furtar de dizer que a origem da visão psicologizante relacionada ao indivíduo está enraizada na influência que a Geografia Humanística ${ }^{15}$ estadunidense recebeu da psicologia de Jean Piaget. Esta prática já havia desconfortado Milton Santos e em sua crítica à Geografia Humanística, sobretudo pelo trato que é dado ao indivíduo, afirma que:

Aquilo que se chama a prática individual não pode ser confundido com a prática coletiva, ou melhor, com a prática social. O que se chama de prática individual são os comportamentos dos indivíduos na vida corrente, conjunto de atitudes e de gestos com os quais cada homem se insere na vida de sua própria coletividade como produto e como cidadão. Desse tipo de prática, diz-se frequentemente que ela comporta uma parcela importante de escolha pessoal, de indeterminação e do que se chama sorte (SANTOS, 2005, p. 129).

Esta escolha pessoal sobre a qual alerta Milton Santos, traduzida na prática individual que está expressa na Geografia Humanística estadunidense, é muito próxima da adoção da instância individual da Tendência Humanista-cultural brasileira. Tal noção põe em relevo um sujeito, e o nível em que ele se encontra é o segredo guardado pela tendência. O apelo ao individual surge na tentativa de se criticar uma Geografia de cunho marxista e que teria na práxis social seu foco maior de análise. E, neste sentido, a assertiva de Milton Santos é incontornável:

Se levarmos em conta as práxis individuais ou, melhor dito, as correspondentes a cada indivíduo, encontraríamos uma multiplicidade de objetos de referência. Desse modo, a realidade, o objeto real, pareceria pulverizado, dividido em tantos objetos particulares quantas são as pessoas a quem sua realidade concerne. Em outras palavras, o objeto em si perderia sua realidade e, então, nenhum conhecimento dele, como o que ele é, seria possível (SANTOS, 2005, p. 129).

Ao se investir na pulverização correspondente a qualquer indivíduo em sua particularidade, abre-se um contato com a intimidade inalcançável ao saber geográfico. A inviolabilidade do indivíduo é a marca maior da impossibilidade de se pensá-lo como real espacial, ou real geográfico. O sujeito como voz da modernidade não é um somatório das impressões individuais, ele é, essencialmente um coletivo, ao menos numa perspectiva fenomenológica-existencial. É o que Augustin Berque, ${ }^{16}$ expoente da Geografia Cultural francesa, traz ao falar do sujeito em sua relação com a paisagem, entendendo-a como Marca e como Matriz. Ele afirma que a paisagem é marca:

[...] pois expressa uma civilização, mas também é uma matriz, porque participa dos esquemas de percepção, de concepção e de ação - ou seja da cultura - que canalizam, em um certo sentido, a relação de uma sociedade com o espaço, e com a natureza e, portanto, a paisagem do seu ecúmeno (BERQUE, 2004, p. 84).

Ao longo de todo o texto, Berque deixa claro que a manifestação concreta da paisagem é passível de análise, "mas ela existe em primeiro lugar em sua relação com o sujeito coletivo" (BERQUE, 2004, p. 84). A afirmação é exatamente para asseverar que o sujeito que ele trata não é aquele restrito a uma

15 O termo humanística é utilizado aqui para designar estritamente aquela produção que sofreu influência específica das obras de Jean Piaget e que aparece na primeira investida desta tendência em solo nacional.

16 Augustin Berque é um autor que ainda não figura de maneira central para a Tendência Humanista-cultural brasileira, algo que se configura como um equívoco, pois sua obra Écoumène trabalha com alguns conceitos que são fundamentais para ativar futuros desdobramentos que podem nutrir outros caminhos. No que se refere ao conceito de médiance o autor oferece pistas para pensarmos outro noção de vivido, para Berque a médiance é "esta divisão em duas metades, que amplia nosso ser do íntimo de nosso corpo animal até o horizonte de nosso mundo, é o momento estrutural de nossa existência" (BERQUE, 1999, p. 204). Por enquanto, neste trabalho, preferi trazer a ideia de sujeito coletivo, pois dialoga mais fortemente com a discussão travada. 
dimensão individual. Sua Geografia Cultural quer entender o sujeito como coletividade que deixa marcas. O sujeito, que é coletividade, não deve ser confundido com qualquer outra feição que não seja a expressa pelo que se entende por sociedade. Se o sujeito é coletividade, temos uma questão basilar posta para a Geografia; afinal, os trabalhos que estão reduzindo seu objeto de pesquisa ao indivíduo pretendem conhecer o real exposto naquela experiência empírica vivida por cada pessoa. A Geografia que se intitula humanista, apesar de ter em sua base uma influência da fenomenologia, vem se esquivando da contenda; o desafio da tendência humanista-cultural está no enfrentamento da dúvida sobre a possibilidade de se considerarem estes estudos como sendo inerentes ao escopo geográfico. O ganho conquistado no movimento de renovação, sobretudo pela via marxista, imputa ainda hoje à Geografia ter que dizer do mundo da prática social. É da natureza de qualquer ciência social, que fala dos homens materiais, ${ }^{17}$ se enveredar pelos caminhos da práxis: "É à prática social que se deve reservar a fórmula simplificada de prática ou práxis. Sem isto, tornar-se-ia impossível apreender e materializar o próprio objeto da atividade do conhecimento" (SANTOS, 2005, p. 129). Não quero dizer que todo estudo só é valido a partir da noção de práxis; trago Milton Santos muito por ele ter sido um pensador da Geografia que visitou outras correntes e influencias filosóficas. A pergunta aqui imposta é exatamente sobre os alicerces de uma tendência que busca pensar o sujeito por outras vias. Nesta medida, a Geografia em sua trajetória se vê diante do desejo sartreano de construir um reino humano, com valores que sejam distintos daqueles presentes no reino material (SARTRE, 1973). No interior da ideia de prática social, há nuanças de intersubjetividade, na medida em que não habitamos sozinhos. Somos seres sociais. Vale lembrar que não há uma subjetividade sem sua referência a outra subjetividade, entrelaçada com a objetividade do mundo:

[...] a subjetividade que nós, aí, atingimos, a título de verdade, não é uma subjetividade rigorosamente individual, porque demonstramos que, no cogito, nós não descobrimos só a nós, mas também aos outros. Pelo penso, contrariamente à filosofia de Descartes, contrariamente à filosofia de Kant, atingimo-nos a nós próprios em face do outro, e o outro é tão certo para nós como nós mesmos (SARTRE, 1973, p. 21-22).

O que está ainda em suspenso é exatamente a capacidade de reformular a subjetividade no âmbito da Geografia, conduzida ao íntimo desordenado de cada indivíduo, em sua "multiplicidade de objetos de referência". O contexto em desdobramento almeja à sua autenticidade perante as diversas correntes de pensamento da Geografia e, como tal, terá que decidir sobre a amplitude que deseja conferir ao indivíduo. Não será sobre um monolito de uma ideia de sociedade que se construirá uma forte corrente de pensamento, e não será também através de miríades de olhares e pensares dos mais diversos indivíduos que a solidez desta tendência humanista-cultural irá se manter.

\section{CONSIDERAÇÕES FINAIS}

Em 2011 tive a oportunidade de realizar uma entrevista com Jean-Marc Besse, filósofo interessado em desvendar o conceito de paisagem e que, entre outras publicações, escreve um texto intitulado "Geografia e existência", que figura ao final da publicação da obra L'homme et la terre, de Éric Dardel. $\mathrm{Na}$ ocasião, pude questioná-lo acerca da influência desta obra de Dardel sobre a Geografia Humanista e também sobre as configurações da Geografia Humanista em geral. Resumidamente, Besse dizia ser necessário fazer uma distinção "entre a Geografia de língua inglesa e a Geografia de língua francesa", porque "a recepção, o uso e a mobilização de referências à fenomenologia e ao existencialismo são muito, muito diferentes"; em seu entendimento "não são as mesmas Geografias".

No presente texto, busquei mostrar que essas duas fontes de influências penetraram em solo brasileiro com um nível de aproximação um tanto maior em relação aos trabalhos anglofônicos; contudo, a partir de uma leitura particular. Em outro texto, pretendo me debruçar sobre a influência francesa, principalmente a partir de nomes como Augustin Berque, Paul Claval, Éric Dardel e do próprio Jean-Marc Besse. A empreitada aqui empregada procurou demonstrar certos limites interpretativos da Geografia brasileira, tendo em vista que o olhar plural confeccionou o cenário atual; afinal, como afirmou Besse em nossa entrevista,

\footnotetext{
17 O termo material está no sentido conferido pelo Materialismo Histórico, neste sentido pode-se ainda, afirmar que a materialização se dá na relação direta entre a sociedade e a paisagem, que, para Milton Santos, é a síntese do conceito de espaço.
} 
[...] a Geografia humanista, que, na verdade, é um termo, de fato, um pouco confuso, porque, na realidade, por trás do modo de ser da Geografia humanista existem correntes muito diferentes que se desenvolveram, e a referência à fenomenologia não foi precisa, não foi exata, é uma referência bastante vaga à fenomenologia (BESSE, 08/06/2011). ${ }^{18}$

Esta afirmação conduziu, à época, uma reflexão sobre os caminhos da Geografia brasileira e que aqui trouxe como a construção do viés principal do que chamei de tendência humanista-cultural da Geografia brasileira. Ao trazê-la para o centro da discussão, apresentei a instabilidade existente em relação à chegada de Frémont e o conceito de espaço vivido com marcante traço calcado na psicologia, em conjunto com a noção de mundo vivido, incorporada por uma leitura da Geografia Humanista anglo-saxônica. Tal instabilidade é expressa como um afastamento dos princípios basilares de Husserl, quando este buscou enveredar pela trilha do vivido; afinal, não haveria espaço para a dinâmica íntima do indivíduo como produtora de sentido universal, algo que para Ernildo Stein teria sido a fratura deixada pelo filósofo alemão.

Ao confrontar com a ideia de um sujeito compreendido na esfera psicológica, ou do indivíduo em sua realidade empírica primeira, busquei em Alain Touraine e na noção da emergência do sujeito na modernidade como criação, e em Jean-Paul Sartre, Milton Santos e, ainda, em Augustin Berque, os caminhos para compreender um sujeito que aponte para a coletividade. Esta ação se faz necessária, por perceber que há uma impossibilidade de visitar os indivíduos nos estudos geográficos sem que se realize uma etnografia nos moldes da antropologia ou no mínimo uma análise dos sujeitos com a peculiaridade e a intimidade que fazem os psicólogos, técnicas que precisariam ser interpretadas pela Geografia como ciência que não dispensa um olhar para o social, e tampouco imagina lugares a partir da vida privada.

O desejo e a necessidade de pensar sujeitos na Geografia assumem importância crucial em tempos de inquietude em relação aos limites do social; caberiam, de fato, outras formas de vislumbres investigativos, e certamente o sujeito, como coletividade, é um caminho importante a ser seguido. Resta como lidar com a sanha por descobrir cada indivíduo pesquisado em suas particularidades invioláveis concernentes à tendência humanista-cultural. Algo que muito vem contribuir com o debate e, em larga medida, pode dialogar com matrizes de pensamento que não se esquivam de pensar a sociedade. O risco é inevitável, não há mais volta.

\section{REFERÊNCIAS}

ALMEIDA, M. G. Aportes teóricos e os percursos epistemológicos da geografia cultural. Revista GeoNordeste, n. 1, p. 33-54, 2008.

AMORIM FILHO, O. B. A pluralidade da geografia e a necessidade das abordagens culturais. In: KOZEL, S.; SILVA, J. C.; GIL FILHO, S. F. (Orgs.). Da percepção e cognição à representação: reconstruções teóricas da geografia cultural e humanista. São Paulo/Curitiba: Terceira Margem/NEER, 2007. p. 15-35.

BERQUE, A. Écoumène. Paris: Éditions Belin, 1999.

Paisagem-marca, paisagem-matriz: elementos da problemática para uma geografia cultural. In: CORREA, R. L.; ROSENDAHL, Z. (Orgs.). Paisagem, tempo e cultura. Rio de Janeiro: EDUERJ, 2004. p. 84-91.

BESSE, J.-M. Entrevista concedida por Jean-Marc Besse, no dia 08 de junho de 2011, na Unité de Recherche Géographie-Cités (UMR 8504), Université Paris I, 2011. Éditions du CHTS, 1990.

Géographie et existence d'après l'ouvre d'Eric Dardel L'homme et la terre. Paris:

BUTTIMER, A. Aprendendo o dinamismo do mundo vivido. In: CRISTOFOLETTI, A. Perspectivas da Geografia. São Paulo: Difel, 1985. p. 165-193.

18 "[...] la géographie humaniste, qui est un terme à vrai dire un peu confus, en réalité parce que derrière le mode géographie humaniste, en fait il y a des courants très différents qui se sont développés et la référence à la phénoménologie [...] n'a pas été précise, n'a pas été exacte, c'est une référence assez vague à la phénoménologie." 
CHAUÍ, M. S. Vida e obra. In: HUSSERL. Coleção Os pensadores. São Paulo: Editora Nova Cultural 1996.

CLAVAL, P. La géographie sociale et culturelle. In: BAILLY, A. (Org.). Les concepts de la géographie humaine. Paris: Armand Colin, 2004. p. 99-110.

COLESANTI, M. T. M. A perspectiva humanista: o resgate do lugar pela geografia no Brasil. I Colóquio Brasileiro de História do Pensamento Geográfico. Rio Claro: Universidade Estadual Paulista, 2007.

CORREAA, R. L.; ROSENDAHL, Z. Geografia cultural no Brasil. Revista da ANPEGE, v. 1, p. 97-102, 2005. https://doi.org/10.5418/RA2005.0202.0008

COSGROVE, D. A geografia está em toda parte: cultura e simbolismo nas paisagens humanas. In: CORREAA, R. L.; ROSENDAHL, Z. (Orgs.). Paisagem, tempo e cultura. Rio de Janeiro: EDUERJ, 2004. p. 92-122.

CRISTOFOLETTI, Antônio. Perspectivas da geografia. São Paulo: Difel, 1985. p. 165-193.

DARDEL, E. L'homme et la terre. Paris: Éditions du CHTS, 1990.

FRÉMONT, A. La région, espace vecú. Paris: Flammarion, 1999.

GOMES, P. C. C. Geografia e modernidade. Rio de Janeiro: Bertrand Brasil, 2003.

GRATÃO. L. H. B. (À) luz da imaginação! "O Rio" se revela na voz dos personagens do lugarAraguaia! Caderno de Geografia, v. 17, n. 28, p. 89-120, $1^{\circ}$ sem. 2007.

HOLZER, W. A geografia humanista - sua trajetória de 1950 a 1990. Dissertação (Mestrado em Geografia) - Rio de Janeiro: UFRJ. 1992

O conceito de lugar na geografia cultural-humanista: uma contribuição para a geografia contemporânea. Revista GEOgraphia, ano V, n. 10, p. 113-123, 2003.

HUSSERL, E. Ideas relativas a una fenomenología pura y una filosofía fenomenológica. México: Fondo de cultura econômica, 1949.

KOZEL, S. Representação do espaço sob a ótica dos conceitos: mundo vivido e dialogismo. Anais XVI Encontro Nacional dos Geógrafos. Porto Alegre: AGB, 2010.

LOWENTHAL, D. Geografia, experiência e imaginação. In: CRISTOFOLETTI, A. Perspectivas da geografia. São Paulo: Difel, 1982. p. 103-141.

LYOTARD, J.-F. A fenomenologia. Lisboa: Edições 70, 1999.

MACIEL, C. A. Morfologia da paisagem e imaginário geográfico: uma encruzilhada onto-gnosiológica. GEOgraphia, ano 3, n. 6, p. 99-117, 2002. https://doi.org/10.22409/GEOgraphia2001.36.a13412

MOREIRA, R. Assim se passaram dez anos: a renovação da geografia brasileira no período 19781988. Caderno Prudentino de Geografia, p. 5-39, 1992.

O discurso do avesso. Rio de Janeiro: Dois Pontos, 1987.

NOGUEIRA, A. R. B. Por uma outra geografia radical: compreendendo os lugares sob um olhar fenomenológico. I Colóquio Brasileiro de História do Pensamento Geográfico. Rio Claro: Universidade Estadual Paulista, 2007.

Uma interpretação fenomenológica na geografia. Anais do X Encontro de Geógrafos da América Latina. São Paulo: USP, 2005.

OLIVEIRA, C. D. M.; CAVALCANTE, T. V. O estudo da terra como lar das pessoas. GEOUSP Espaço e Tempo, v. 25, p. 59-72, 2009. https://doi.org/10.11606/issn.2179-0892.geousp.2009.74111

OLIVEIRA, L. Humanismo na geografia: a contribuição brasileira. I Colóquio Brasileiro de História do pensamento geográfico. Rio Claro: Universidade Estadual Paulista, 2007.

SANGUIN, A.-L. La géographie humaniste ou l'approche phénoménologique des lieux, des paysages et des espaces. Annales de Géographie, t. 90, n. 501, p. 560-587, 1981. https://doi.org/10.3406/geo.1981.20040 
SANTOS, B. S. A crítica da razão indolente. Contra o desperdício da experiência. São Paulo: Cortez, 2000.

SANTOS, M. Metamorfoses do espaço habitado. São Paulo: Hucitec, 1986

Para que a geografia mude sem ficar a mesma coisa. Revista RA'EGA - O Espaço Geográfico em Análise, n. 9, p. 125-134, 2005. https://doi.org/10.5380/raega.v9i0.3452

SARTRE, J.-P. O existencialismo é um humanismo. São Paulo: Editora Abril, 1973.

SAUER, C. A morfologia da paisagem. In: CORREAA, R. L.; ROSENDAHL, Z. (Orgs.). Paisagem, tempo e cultura. Rio de Janeiro: EDUERJ, 2004. p. 12-74.

SERPA, A. S. P. Culturas transversais: um novo referencial teórico-metodológico para a geografia humanista e cultural? KOZEL, S.; SILVA, J. C.; GIL FILHO, S. F. (Orgs.). Da percepção e cognição à representação: reconstruções teóricas da geografia cultural e humanista. São Paulo/Curitiba: Terceira Margem/NEER, 2007. p. 36-56.

STEIN, E. Mundo vivido: das vicissitudes e dos usos de um conceito da fenomenologia. Porto Alegre: EDIPUCRS, 2004.

TOURAINE, A. Crítica da modernidade. Petrópolis: Vozes, 1999.

TUAN, Y. F. Topofilia: um estudo da percepção, atitudes e valores do meio ambiente. São Paulo: Difel, 1980.

Recebido em: 20/09/2020

Aceito para publicação em: 16/11/2020 